\title{
ESTUDO DE CASO APLICADO EM UMA MULTINACIONAL DO SETOR ALIMENTÍCIO SOBRE O INDICADOR DE DESEMPENHO ON TIME COMO MEIO DE AVALIAÇÃO DO NÍVEL DE SERVIÇO LOGÍSTICO OFERECIDO
}

Hercília Rodrigues Barbosa (UFPE) herciliarodrigues@ hotmail.com Manoel Lopes de Andrade Neto (UFPE) manoel.lopes.netto@gmail.com Marcele Elisa Fontana (UFPE) marcele.elisa@ufpe.pe

\section{Resumo}

O referido trabalho foi apresentado através de um estudo de caso aplicado em uma multinacional do setor alimentício, de forma a avaliar do nível serviço prestado aos clientes que são atendidos por um de seus Centros de Distribuição (CD). O indicador de desempenho utilizado para o estudo, denominado por On Time, faz parte da composição On Time In Full (OTIF), que tem o intuito de controlar os processos logísticos. Após a coleta de dados, através de reuniões e da base de dados utilizada pela empresa (Tableau), foi possível identificar as principais falhas do processo de entrega, fazendo o uso de ferramentas da qualidade. Em seguida, foram propostas sugestões de melhoria no engarrafamento no trânsito e no perfil do veículo responsável pela entrega, visando a fidelização e satisfação de seus clientes, no que diz respeito ao nível de serviço prestado pela organização.

Palavras-Chaves: Logística; Nível de serviço; Indicadores de Desempenho; On Time.

\section{Introdução}

A crescente concorrência das organizações faz com que elas procurem fontes alternativas de inovações, melhores condições de entrega dos produtos, garantia de qualidade, melhores formas de pagamento, entre outros estímulos. Neste contexto, a logística assume um papel muito importante dentro das empresas, no que diz respeito, principalmente, ao atendimento dos seus objetivos estratégicos. O diferencial competitivo de uma empresa pode estar ligado diretamente a satisfação do cliente quanto aos serviços prestados pela mesma. Para tanto, o uso de indicadores chave de desempenho pode auxiliar no gerenciamento dos sistemas logísticos. O gerenciamento se dá através de avaliações da qualidade do serviço prestado, para, assim, sinalizar desvios em torno dos objetivos traçados inicialmente.

Desta forma, o presente trabalho focou em um indicador de nível de serviço logístico que mede a porcentagem de ordens de pedidos que são atendidos dentro do prazo exigido pelo 
cliente. $\mathrm{O}$ estudo foi realizado em uma empresa do setor alimentício que tem diversos centros de distribuição espalhados pelo país com uma malha logística delimitada através das regiões do Brasil de forma a avaliar o nível de serviço logístico prestado aos clientes atendidos diretamente pelo Centro de Distribuição.

No caso da empresa estudada o prazo da entrega está relacionado com a qualidade em que o produto chega até o cliente e isso se dá pelo fato de que produtos resfriados e congelados exigem temperaturas específicas para a sua conservação. Para chegar a níveis de serviço adequado é extremamente importante ter um controle eficiente dos processos, que significa comparar se o desempenho planejado está de acordo com os objetivos estratégicos da empresa e, para isso, é necessário buscar formas de mensurar se o desempenho real está alinhado com o planejado. Caso não exista esse alinhamento, é necessário fazer uso de indicadores de desempenho, pois é através deles que se consegue mensurar e avaliar qual o desempenho dos processos logísticos para, em seguida, detectar se houve desvios em relação ao que se foi planejado para, consequentemente, implantar soluções viáveis para atingir pontos de melhoria.

Para medir e acompanhar se os prazos das entregas estão satisfazendo as expectativas dos clientes, na empresa em estudo, é utilizado um indicador denominado por On Time (significa "no tempo") que serve para identificar qual é o percentual de ordens de pedido que foram atendidas no prazo estipulado, com relação ao total de ordens enviadas no mesmo período (semana, mês, ano).

A empresa estudada é considerada a terceira maior exportadora do País, líder mundial na exportação de aves e com uma considerável participação no PIB Brasileiro. O setor brasileiro de alimentos registrou um crescimento de 2,08\% em faturamento no ano de 2018, atingindo $\mathrm{R} \$ 656$ bilhões, somadas exportação e vendas para o mercado interno, o que representa 9,6\% do PIB, segundo a pesquisa conjuntural da Associação Brasileira da Indústria de Alimentos (ABIA, 2019). Para tanto, entende-se que a concorrência neste mercado é elevada e com certo grau de substituição dos produtos, não havendo uma fidelidade grande dos consumidores. Portanto é importante que as empresas procurem estratégias para adquirir vantagens competitivas frente aos seus concorrentes, utilizando, assim, de recursos e oportunidades dos diversos setores da mesma.

Nas próximas secções serão abordados em mais detalhes os aspectos teóricos que envolvem a problemática deste trabalho (secção 2), bem como a metodologia utilizada no estudo (secção 
3), os resultados e propostas desenvolvidas para alcançar as melhorias esperadas na organização analisada (secção 4) e, por fim, as considerações finais (secção 5).

\section{Fundamentação teórica}

\subsection{Logística}

A logística é um instrumento antigo usado principalmente para contexto militar. Existem diversos exemplos históricos da aplicabilidade logística, tais como linhas de suprimento logístico, ou mesmo a falta deles, deram forma para cruzadas militares de Alexandre, o Grande, Napoleão, a primeira e segunda guerra mundial (GRANT, 2013).

A palavra "logística" era relacionada as atividades do ramo empresarial, embora as preocupações que definem os estudos sobre logísticos estejam nas problemáticas desde no início da história humana. Assim, a logística que teve o seu cerne nas atividades militares, passa a ser utilizada no dia a dia dos gestores para compor o hall de soluções que definem a capacidade gerencial de uma organização (NOGUEIRA, 2012).

Entende-se que o objetivo principal da logística não se traduz em favorecer apenas as operações da empresa e direcionar as estratégias do marketing, mas executar os processos de forma assertiva para proporcionar a satisfação do cliente (BOWERSOX; CLOSS, 2009). Para alcançar tais objetivos, os gerentes dispostos dentro do sistema operacional buscam atingir a qualidade de serviço que é definido previamente pelo cliente. Para alcançar tal objetivo, entende-se que é a logística que fomenta as condições reais para que o consumidor possa adquirir o produto/serviço, no tempo desejado e com as condições especificadas garantidas.

Para BALLOU (2010), a métrica para o patamar que gerenciar as atividades logísticas está diretamente ligado aos métodos de administração do nível de serviço logístico prestado para o cliente, assim, é coerente a definição de estratégias para que haja o planejamento do nível de serviço a ser adotado pela organização.

Portanto, entende-se que a logística é um marco transformador das atividades de gerenciamento de uma organização e por isso, observar os métodos e os procedimentos que envolvem a gestão logística é, necessariamente, um ponto crucial para o alcance da maturidade empresarial. 
Já o Centro de Distribuição (CD) é um conceito moderno para área industrial, cuja função ultrapassa as definições dos galpões e almoxarifados e o tornam imprescindíveis para o bom funcionamento do sistema logístico. O objetivo principal do CD é garantir uma resposta rápida para as necessidades dos clientes de determinada área geográfica, o que normalmente é organizado para garantir essa resposta em locais onde não há alcance dos centros produtivos. Assim, pode ser observado como atividades principais de um CD os processos primários de recebimento, movimentação, armazenagem, processamento de pedidos e transporte.

O transporte, por sua vez, é o elo entre os centros consumidores e os centros fornecedores com o menor custo possível. A função de transportar cargas e pessoas existe desde os primórdios da humanidade (LARRANÃGA, 2015; SILVA 2019). Nos dias atuais, o transporte se tornou um dos diferenciais competitivos para a empresa e a ele compete o maior custo das atividades relacionadas à logística. Assim, observa-se que, para as empresas adquirem uma capacidade de promoção de um diferencial competitivo para a área, irá precisar organizar um sistema de transporte que garanta essa competitividade (GOMES, 2004).

Em princípio, qualquer organização é capaz de desenvolver algum nível de serviço logístico se a empresa tiver a disposição para alocar recursos físicos e humanos necessários para esse desenvolvimento. Assim, cada empresa deve estipular como será avaliado o nível de serviço através de seus indicadores de desempenho.

\subsection{Indicadores de desempenho}

Os indicadores de desempenho são processos que são capazes de formular avaliações sobre determinado fenômeno baseando-se em fatos e dados quantitativos, o que garante que as conclusões serão confiáveis. Portanto, para garantir a boa utilização dessas ferramentas analíticas é necessário traduzir os indicadores para não permitir que eles ser tornem duvidosos, sejam de fácil obtenção e tenha uma capacidade de compreensão simples o bastante para dar auxílio a decisões rápidas.

Dentro do que se definem como indicadores, vale ressaltar a importância do Key Perfomace Indicator (KPI) ou, no português, Indicador Chave de Desempenho. Os KPI's podem ser direcionados para a compreensão do processo e o seu método de execução, as formas que o processo é executado, não deixando passar erros que possam comprometer todo o processo. Para o cenário da organização alvo do estudo, baseou-se na utilização do indicador On-Time. 


\subsubsection{On time}

O indicador On Time faz parte da composição do indicador conhecido por (OTIF). Sua sigla representa as letras iniciais dos termos em inglês On Time In Full, utilizado para monitorar a qualidade da entrega de produtos e serviços, o que de acordo com DE OLIVEIRA e ARAÚJO (2009) conceitualmente significa:

- On Time: produtos/serviços devem ser entregues em determinada data, horário ou janela de horas e local, previamente especificado em conjunto com o cliente;

- In Full: produtos/serviços devem estar dentro das especificações acordadas com o cliente: qualidade intrínseca, dimensões, quantidade, perfeitas condições físicas e quaisquer outros atributos específicos de cada setor.

O OTIF mede quantos pedidos foram realizados conforme o que foi solicitado/contratado em termos de prazo e qualidade. Assim, calcula-se para cada pedido dois itens: On Time, se o pedido foi entregue no prazo e o In full, se o pedido foi entregue completo e perfeito conforme contratado. Ainda, conforme DE OLIVEIRA e ARAÚJO (2009), em relação à sua métrica, o indicador OTIF é considerado do tipo binário (atende/não atende) relacionando, assim, o volume e a data entregue, ou seja, a medida do pedido perfeito.

O presente estudo foi voltado apenas para a análise de um dos componentes do indicador, o On Time, onde o mesmo está voltado para o conceito de prazo de entrega. Sendo consideradas como "ordem On Time", as ordens que foram entregues na data desejada e "ordens a entregar”, as que estão para ser entregues, isso em algum período especificado, local, cliente, etc., podendo ser definido através da Equação 1.

$$
\begin{gathered}
\% \text { On Time }=\frac{\text { Total de ordens On Time }}{\text { Total de ordens a entregar }} \times 100 \\
\text { Fonte: Autor (2019) }
\end{gathered}
$$

A importância deste indicador está voltada para o aumento de performance das entregas, melhoramento de envio e recebimento de produtos, redução de custos e fidelização dos clientes. 


\section{Metodologia}

O presente trabalho se constitui em um estudo de caso, o qual teve o objetivo de analisar um determinado tema dentro de um caso real, trazendo explicações e questionamentos sobre como e porque este caso ocorre.

Este trabalho possui uma natureza qualitativa, pelo fato de ter levantado aspectos atinentes do indicador em estudo, embora o tratamento dos dados tenha sido de forma quantitativa. A abordagem está voltada ao conteúdo da revisão da literatura dos assuntos referentes à logística, nível de serviço e indicadores de desempenho que ofereceram subsídios para a construção do trabalho no todo. A coleta de dados se deu através de relatórios e base de dados disponibilizados no sistema de informação da empresa, o Tableau.

O estudo de caso foi aplicado no processo logístico de uma empresa do setor alimentício, mais precisamente voltado para o um indicador que mede o nível de serviço prestado pelas entregas realizadas nos estados de Pernambuco e Paraíba, que provém do carregamento de veículos do centro de distribuição localizado em Pernambuco.

\section{Estudo de caso}

O estudo de caso foi realizado em uma empresa, considerada líder na produção de alimentos resfriados e congelados no Brasil, dispondo de mais de 03 mil itens em seu portfólio, distribuídos entre os segmentos de carnes, lácteos, margarinas, massas, pratos congelados, vegetais congelados, entre outros. A empresa possui 60 unidades industriais no Brasil e outras 03 no exterior, exportando seus produtos para mais de 100 países por meio de uma ampla e complexa estrutura de distribuição especializada na cadeia de frio, que contempla 36 centros de distribuição, chegando nos mais variados lugares do mundo.

A malha logística da empresa é composta por três centros de distribuição (CD) localizados em Pernambuco, Bahia e Ceará. Além disso, inclui 07 Transit Points (TSP's) localizados no Maranhão, Alagoas, Sergipe, Piauí e Rio Grande do Norte. Neste trabalho foi estudado o CD de Pernambuco, o qual apresenta os seguintes processos logísticos: recebimento de produtos 
das fábricas da companhia e/ou dos CD's, armazenagem, separação, expedição, faturamento e entrega ao cliente.

O fluxo de atendimento ao cliente quanto ao pedido dos produtos até a chegada ao estabelecimento pode ser seguido de acordo com a Figura 1:

Figura 1 - Fluxograma de atividades logísticas

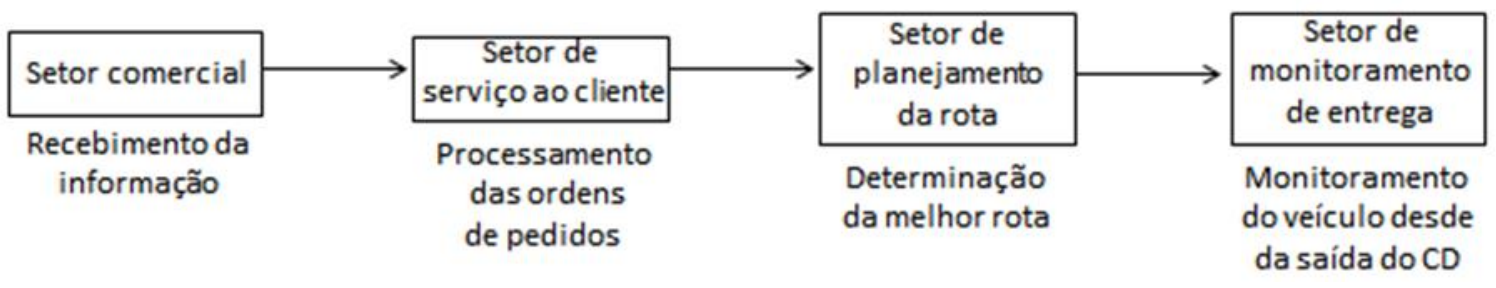

Fonte: Autor (2019)

\subsection{Identificação do problema}

Nos meses de julho, agosto e setembro foram coletados os dados referentes as operações logísticas realizadas. Com o uso da Equação 1, verificou-se que julho foi o mês em que mais "perdeu On Time" em relação à quantidade de ordens que deveriam ser entregues no prazo, das 30.175 ordens processadas, apenas $81,12 \%$ delas foram entregues na data solicitada, ou seja, garantindo o prazo estabelecido pelo cliente.

A Figura 2 mostra o resultado do indicador On Time (real) e a meta para o período.

Figura 2 - On Time meta versus real

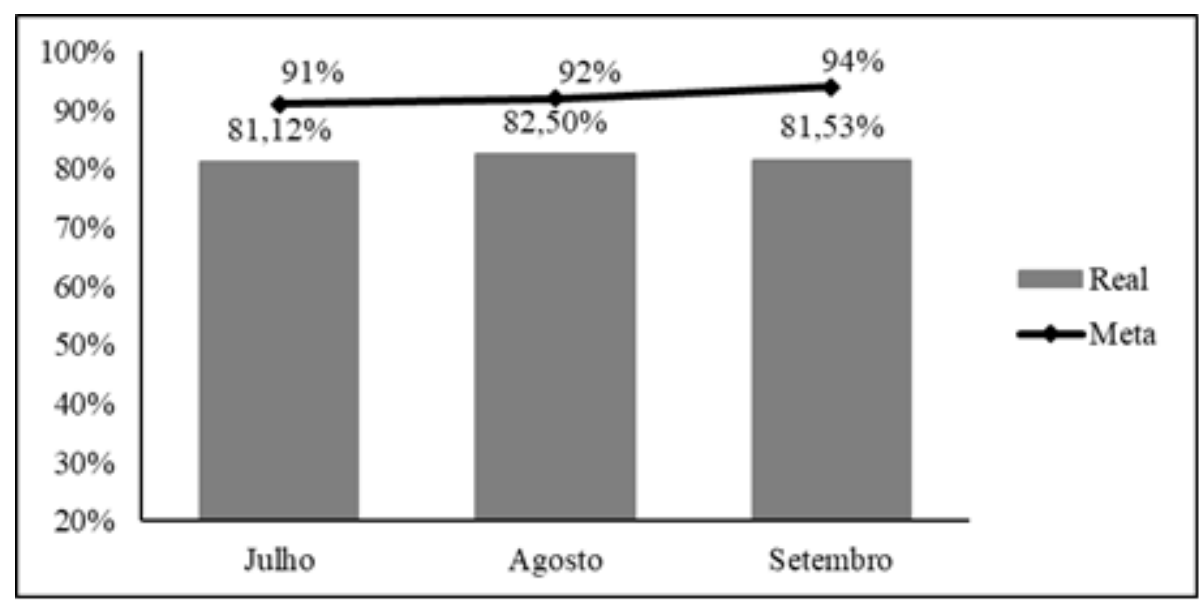

Fonte: Autor (2019) 
Com o gráfico apresentado na Figura 2 dos três meses analisados como base para o estudo, é plausível entender como funciona o indicador e, assim, analisar a divergência que se tem em cada mês com relação a meta estipulada pela companhia.

\section{Resultados e análises}

A partir da coleta de dados realizada por meio da identificação do problema inserido neste estudo, foi observado a divergência da meta. A investigação dessas características se deu mediante uma visão ampla e sob vários pontos de vista da porcentagem do indicador On Time dos meses que estão voltados para o estudo, contemplando, assim, os meses de julho, agosto e setembro.

Os dados obtidos foram analisados/agrupados/organizados em várias formas e foi escolhido o critério de estratificação por capital federativa, com o objetivo de conhecer melhor o problema estudado e as principais origens do mesmo.

A primeira estratificação do indicador realizada foi por capital que o CD atende, de acordo com a base de dados disponibilizados pela empresa no software Tableau, o qual proporciona a utilização dos dados e agrupamento de diversas formas para uma análise do indicador. $\mathrm{O}$ gráfico na Figura 3 mostra a quantidade de ordens que se não foram atendidas no prazo requisitado pelo cliente.

Figura 3 - Estratificação do On Time por Capital

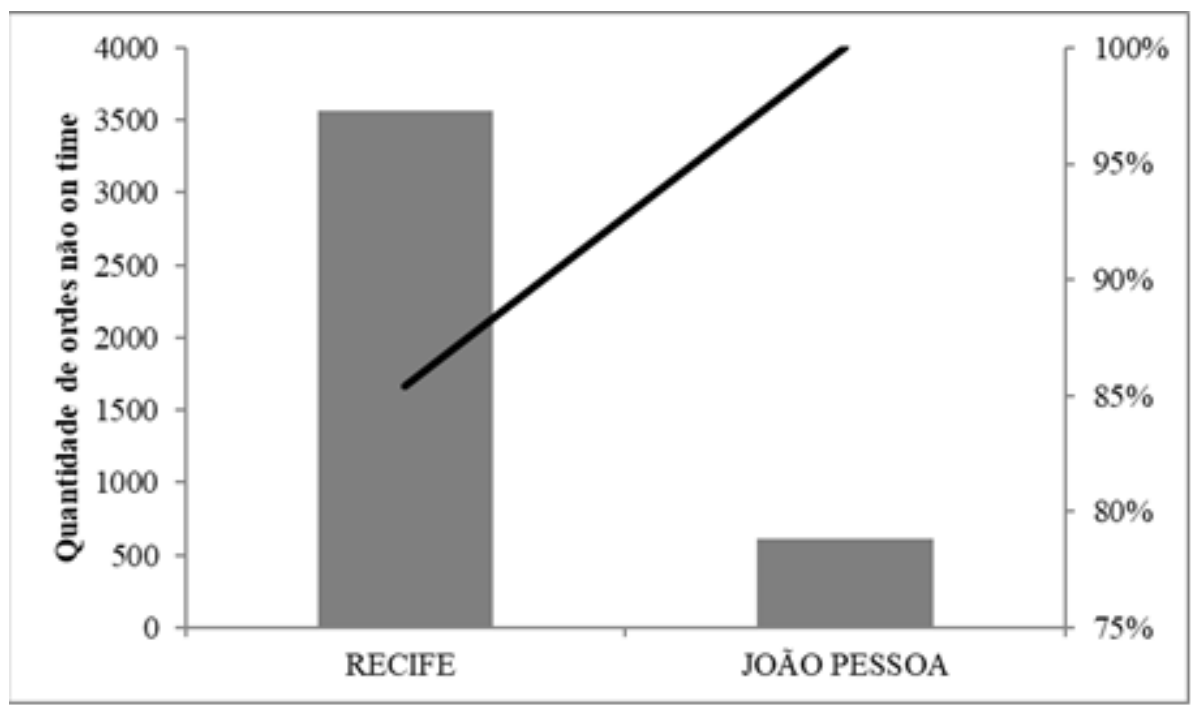


É possível observar que Recife foi a capital mais crítica no que diz respeito à esta primeira estratificação do indicador. Sendo a que se apresenta com a capital que mais obteve ordens não On Time, ou seja, ordens que não foram atendidas no prazo desejado.

Para detalhar melhor o problema foi escolhido a capital mais crítica para priorizar os aspectos mais importantes e, assim, realizar uma análise do problema de forma mais detalhada. Com isso o critério estabelecido foi observar em quais dias da semana essas 3569 ordens foram perdidas, como mostra a Figura 4.

Figura 4 - Estratificação de On Time por dia da semana

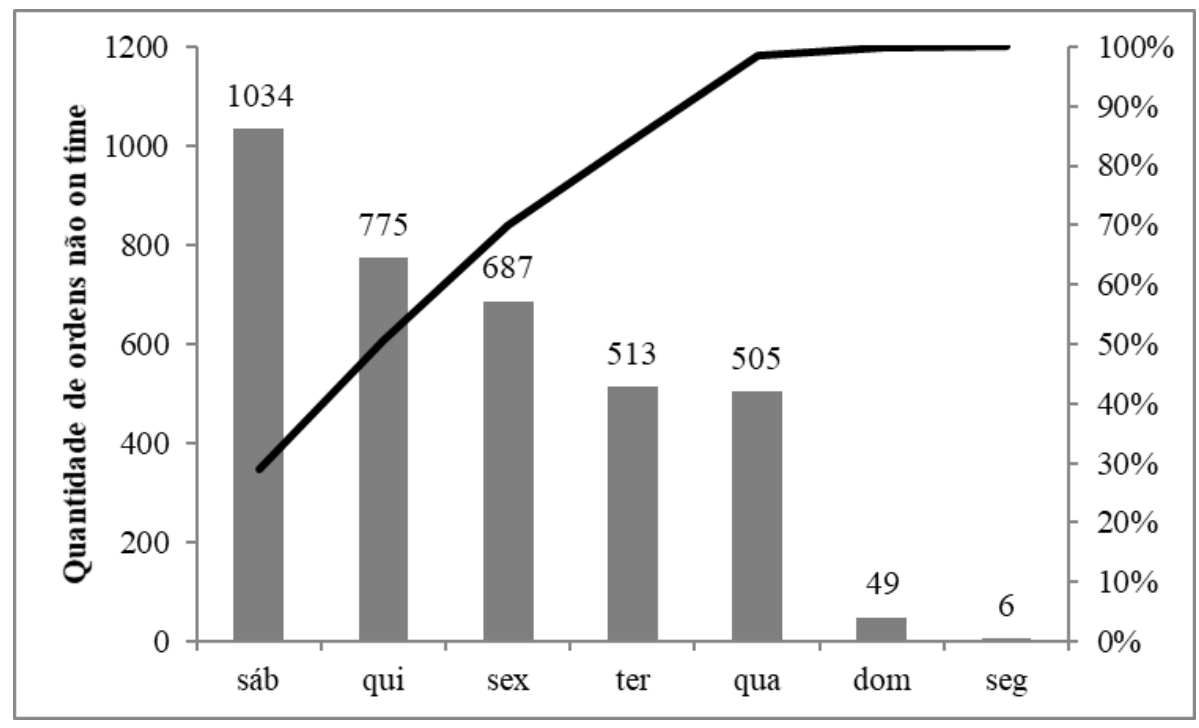

Fonte: Autor (2019)

A fim de descobrir quais as principais causas que estavam causando as lacunas do indicador nos meses referentes ao estudo do trabalho, foi necessário se ter um conhecimento crítico da real situação do processo logístico da empresa estudada. Com isto, foi feito uma estratificação de informações em reuniões semanais, sobre os principais motivos que estavam interferindo nos processos de entrega, de uma forma voltada para os dias das semanas mais críticos na cidade de Recife. Assim, os principais motivos para as falhas no processo de entrega foram elencados como sendo:

- Engarrafamento no trânsito;

- Perfil do veículo não compatível com a entrega;

- Retenção de veículo em clientes de grandes redes; 
- Quantidade de entrega acima da capacidade de realização das entregas do referente dia;

- Falta de lugar para estacionar próximo aos pontos de descargas dos clientes;

- Falta de disponibilidade de veículo, ficando com a carga expedida porém sem veículo para realizar a entrega;

- Atraso na largada do veículo no CD.

Em seguida, foi utilizado o Gráfico de Pareto a finalidade de atuar nas principais falhas do problema. O resultado pode ser visualizado na Figura 5.

Figura 5 - Gráfico de Pareto dos motivos de não On Time

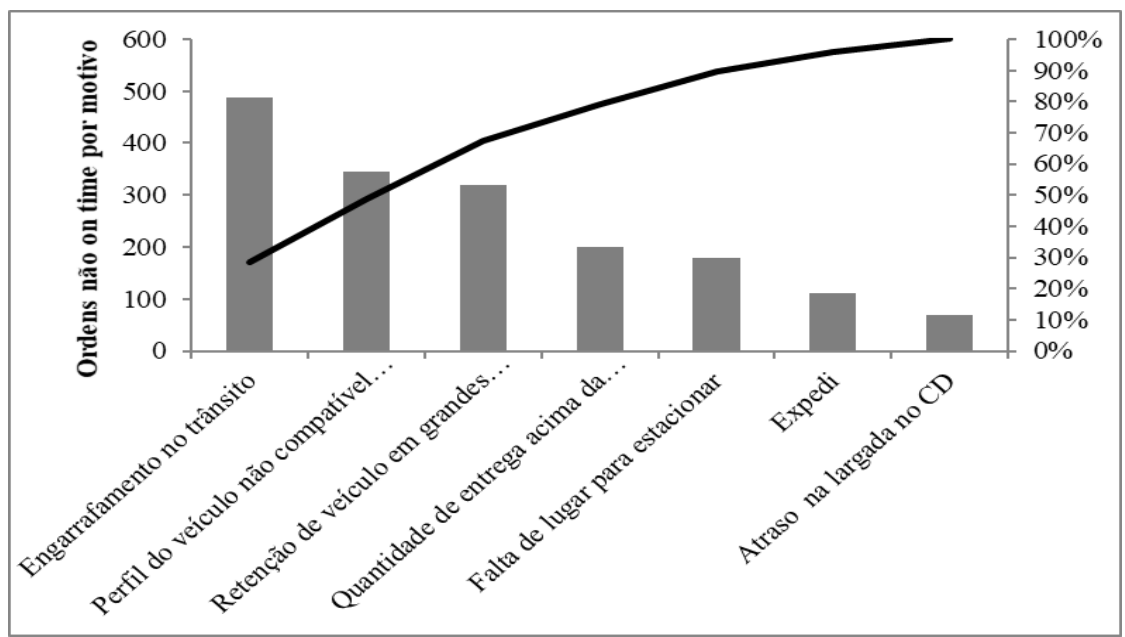

Fonte: Autor (2019)

Os problemas de Engarrafamento no trânsito e Perfil do veículo não compatível com a entrega representam cerca de $70 \%$ dos problemas e, com isso, é mais viável propor melhorias voltadas para estes motivos.

\subsection{Discussões}

Após o estudo acerca do indicador, a mensuração de estratificações e conhecimentos das principais causas, subsídios foram gerados para a elaboração de estratégias de curto e longo prazo para que o indicador atinja resultados positivos, buscando, assim, uma melhoria contínua para o indicador. 
Atualmente o CD está localizado cerca de $50 \mathrm{~km}$ de capital pernambucana, o qual possui uma localização viável. Porém de acordo com o horário de largada dos veículos no $\mathrm{CD}$, o congestionamento no trânsito é imprevisível, fazendo com que o tempo de deslocamento seja alto e, com isso, existe o risco de o cliente não receber seus produtos conforme combinado. Isso é agravado por diversos fatores, tais como: horário restrito de recebimento, jornada de trabalho do motorista, perca de agendamento do recebimento.

Neste caso, a sugestão seria a instalação de um TSP na cidade de Recife, de forma que o mesmo ficaria responsável por atender toda Região Metropolitana de Recife (RMR), já que, segundo dados coletados na empresa, cerca de 2000 clientes que são atendidos pelo CD estão localizados na RMR.

Encontrar o sistema de transporte mais viável para realização de entregas é sempre um desafio para a logística e juntamente a este desafio surge a necessidade de alocação do melhor perfil/tipo do veículo para realização desta atividade, visto que existem clientes que estão localizados de uma forma que exigem um tipo específico de veículo para seu atendimento.

Desta forma é proposto que as entregas na RMR sejam realizadas em veículo do tipo VUC, que tem como característica: largura de 2,2 m, e comprimento de $6,3 \mathrm{~m}$, sendo apropriados para realizar entregas urbanas. Diante deste cenário é possível garantir agilidade nas entregas, tempo de espera, estacionamento e desempenho de veículos vindo a impactar diretamente no indicador On Time.

\section{Conclusão}

$\mathrm{O}$ atendimento das demandas requisitadas por clientes vem representando a necessidade das empresas de buscarem cada vez mais a utilização de estratégias para que, assim, possam se manter no mercado. Diante deste cenário o presente trabalho, teve como objetivo avaliar o processo de entrega dentro do setor de logística de uma multinacional do setor alimentício.

Após o estudo e conhecimento detalhado sobre o indicador On Time, foi possível adquirir conhecimento sobre uma das premissas do significado de logística que é "entregar no prazo certo", de uma forma aplicada a um ambiente organizacional. Através do uso de simples ferramentas de gestão da qualidade, foi concebível verificar algumas falhas no processo 
logístico da empresa estudada e, em seguida, fosse identificado pontos de melhoria e direcionamento com a finalidade de se obter um melhor nível de serviço logístico.

\section{REFERÊNCIAS}

ABIA. Associação Brasileira da Indústria de Alimentos, 2019. Disponível em < https://www.abia.org.br/vsn/tmp_2.aspx?id=393>. Acesso em: 25/09/2019.

BALLOU, Ronald H. Gerenciamento da Cadeia de Suprimentos/Logística Empresarial. 5. ed. [tradução Raul Rubenich]. Porto Alegre: Bookman, 2010.

BOWERSOX, Donald J.; CLOSS, David J. Logística empresarial: o processo de integração da cadeia de suprimento. São Paulo: Atlas, 2009.

GOMES, Carlos Francisco Simões; RIBEIRO, Priscilla Cristina Cabral. Gestão da cadeia de suprimentos: integrada à tecnologia da informação. São Paulo: Thomson, 2004.

GRANT, David B. Gestão de logística e cadeia de suprimentos. São Paulo: Saraiva, 2013.

NOGUEIRA, Amarildo de Souza. Logística empresarial: uma visão local com pensamento globalizado. São Paulo: Atlas, 2012.

DE OLIVEIRA, Ricardo Rezende; ARAÚJO, Riberto de Barros. Otimizando os processos logísticos pela implantação do OTIF com lean seis sigma. Seminário de Logística. São Paulo, 2008.

SILVA, Guilherme Martins. Melhoria do nível de serviço no atendimento ao cliente por meio da estrutura direta de distribuição transit point. Trabalho de Graduação em Engenharia de Produção Mecânica. Guaratinguetá-SP: Unesp, 2011. 